\title{
Health indices for the evaluation and monitoring of health in children and adolescents in prevention and health promotion: a scoping review
}

\author{
Albulena Selmani ${ }^{1,2}$, Michaela Coenen ${ }^{1,2}$, Stephan Voss ${ }^{1,2}$ and Caroline Jung-Sievers ${ }^{1,2^{*}}$ (])
}

\begin{abstract}
Background: Health indicators are used in different settings to monitor health outcomes. Child and adolescent health is arguably one of the most important areas for the application of indices and indicators in prevention and health promotion. Although single health indicators may be better suited to display the complexity of the health status and its determinants, a selected set of indicators will still offer a complex picture. Therefore, it is argued that a group of indicators combined into an index may offer a pragmatic tool that is easier to use in order to inform stakeholders.
\end{abstract}

Methods: A scoping review was conducted to identify and describe health indices that monitor and evaluate health of children and adolescents and to appraise the quality and value of the identified indices that may guide the further applications of these indices in particular settings. The three bibliographic databases MEDLINE, EMBASE and PsycINFO were searched and a double screening of titles and abstracts as well as double screening of full texts was performed. Indices contained in these studies were analysed in terms of focus and composition and evaluated in terms of quality criteria.

Results: The scoping review identified 36 eligible studies with 18 health indices in six thematic categories. Of the identified indices, seven indices focus on anthropometrical variables, three indices focus on special aspects of newborns and five indices focus on oral health. One index assesses "healthy lifestyle" and one "functional ability" whereas one index a combination of different aspects. Most indices are calculated by using primary health data.

Conclusions: Alone or in combination with single sets of indicators, indices in six major thematic domains may be used as pragmatic tools for monitoring children's and adolescents' health and the evaluation of interventions in health promotion and prevention settings.

Keywords: Health index, Health status indicators, Composite index, Child health, Adolescent health, Evaluation, Monitoring, Surveillance

*Correspondence: cjungsievers@ibe.med.uni-muenchen.de ${ }^{1}$ Institute for Medical Information Processing, Biometry and Epidemiology-IBE, Chair of Public Health and Health Services Research, LMU Munich, Munich, Germany

Full list of author information is available at the end of the article

\section{Background}

Health indicators are used in different settings to monitor health [1]. For example, the World Health Organization (WHO) published a global reference list of 100 core health indicators and health-related SDGs (Sustainable Development Goals) [2]. These are standard sets of core 
indicators prioritized by the global community to provide concise information on the health situation and trends, including responses at national and global levels. Its purpose is to serve as a normative guidance for the selection of standard indicators and their definitions that countries and partners can use for monitoring health in accordance with their respective health priorities and capacity. The Organisation for Economic Co-operation and Development (OECD) compares key indicators and reports on trends over time on population health, risk factors for health and health system performance across OECD members and partner countries [3].

Child and adolescent health is arguably one of the most important areas for the application of indices and indicators in prevention and health promotion [4]. Investment in child and adolescent health and control of adverse determinants will have a long-lasting effect on the whole population, including influencing the health of the next generation [4]. Furthermore, young people are citizens in their own right, yet largely unable to act as self-advocates, particularly at the population level [5]. Children, particularly in infancy, are unable to demand better services for themselves, and therefore information systems such as indicators act as the child's and adolescent's advocate [4].

The World Health Organization describes health as a "state of complete physical, mental and social well-being and not merely the absence of disease or infirmity" [6]. Understanding health as a complex and multidimensional phenomenon, indicators from a wide range of domains come into consideration to evaluate health.

Although a combination of single health indicators may help to understand the complexity of the health status of children, a selected set of indicators may be overcomplex, not least by their sheer numbers or unclear selection or priority setting algorithm [1]. One approach to overcome this complexity and to gain feasibility is to combine indicators into a composite score or index [1]. An index is argued to be more accessible for advocacy and political intervention decisions [1]. Furthermore, a well-designed index may provide a comprehensive vision of a multidimensional phenomenon, to "allow for the setting of national benchmarks and for further international comparisons and is a starting point for analysis and discussion" [1].

However, up to date there is no international consensus on the selection and use of indices despite many narrative reviews, opinions and policy briefs $[1,7]$. Therefore, our objectives were to scope the existing evidence with the two specific aims: a) to identify and describe health indices that monitor and evaluate health of children and adolescents, and b) to appraise the quality and value of the identified indices that may guide the further applications of these indices in particular settings.

\section{Methods}

This scoping review was conducted according to the PRISMA Extension for Scoping Reviews (PRISMA-ScR) [8] and performed according to a preregistered protocol published in the open science framework under the following link: https://osf.io/htgeu.

\section{Search methods for the identification of publications}

The three bibliographic databases MEDLINE, EMBASE and PsycINFO were searched using the following search terms and truncations for a) the population: child, children, teenager*, youth, adolescen"; b) the interest: index*, indices, indicator"; c) the context: health promotion, prevention, monitoring, reporting, public health surveillance, population surveillance. The search strategy was adapted for each database. Database searches were conducted on May 26, 2020 and limited to studies published in English and German. No restriction based on the year of publication was applied. The search strategy was designed by the first author and refined in team discussions with all coauthors. The search strategies for the three databases can be found in Supplementary file 1. Additionally, the references of included reviews were searched for eligible records.

\section{Eligibility criteria}

We applied the following inclusion and exclusion criteria. Criteria were reported according to the PICo (Population, Interest, Context) scheme.

\section{Inclusion criteria}

Population:

- Children/adolescents aged 0-19years, including 19 year olds (according to WHO classifications of adolescence up to 19 years [9])

- Mothers with their children

- Children, adolescents (aged 0-19years) and their parents or family

Interest:

- Health indices combining different health indicators into a composite score

Context:

- Health promotion and prevention

- Monitoring of health indicators

- Oral health 


\section{Exclusion criteria}

Population:

- Aged over 19years

- General population or clinical population

Interest:

- Indicators from areas other than health

- Indicators on Quality of Life

- Studies with the purpose of examining quality criteria of a diagnostic instrument

Context:

- Clinical interventions or clinical settings

- Indicators with a clinical aim such as health care delivery and quality of care

- Association studies and predictors of health indicators

\section{Study selection}

The search results were exported to EndNote and duplicates were removed. All four authors screened the titles, abstracts and full texts of the publications in a stepwise procedure. Firstly, for title and abstract screening the web-based application rayyan was used. All hits were independently screened by the first author and a second coauthor. Any disagreements were resolved through discussion between the two reviewers and in case of disagreement with a third reviewer. Secondly, for the full text screening, the first author screened all publications while $30 \%$ of the publications were independently screened by one of the other authors. Disagreements on study selection and data extraction were solved by consensus and discussion with other reviewers if needed.

\section{Identification of indices}

All eligible studies were searched for indices defined as combining different indicators into a composite score. The definition of an index was based on the definition of the OECD for 'composite Indicator' [10] and Ashraf et al. [11].

\section{Data extraction, management and synthesis}

A customized Excel-based data extraction form was developed. The data chart captured the relevant information on key study characteristics such as authors, year of publication, study type, country, setting, population, number of participants and indices reported. For the data extraction, the first author independently charted data from all eligible articles with $30 \%$ of the data checked and extracted by a second author.

\section{Quality appraisal of indices}

The indices were assessed in terms of five quality domains: index is 1) valid, 2) consistent, 3) sensitive, 4) feasible and 5) defined (see Table 3). These criteria are based on quality criteria used in the Child Health Indicators of Life and Development (CHILD) project [5], which is part of the European Community Health Monitoring Programme (HMP) and are described in the following:

- Validity: Validity is divided into two criteria. Face validity pertains to the "ability of the indicator to measure what it says it measures" [5]. Construct validity "means that the indicator demonstrates an expected empirical relationship with other related indicators" [5].

- Consistency: Consistency is defined as "having reliability in measurement, so that variation in values is true variation not random error" [5].

- Sensitivity: Sensitivity examines whether the index is appropriate to assess change over time [5].

- Feasibility: Feasibility means that "reliable source data must be available" [5].

- Defined: An index is defined, when it is "unambiguous in its data construct" [5].

For each of the criteria validity, consistency and sensitivity, the reviewer's assessment was given in a first column. Additionally, it was indicated how the assessment was reported in the included studies. For this judgement, further literature was consultated in case that no information could be retrieved from the study itself. It is further indicated whether the data collected to calculate the index is available from routine data, or whether primary studies were necessary to collect the data. For the criterion defined, it was assessed whether there is a clear guideline, such as a formula for calculating the index. Further literature was enquired if the information was not contained in the studies per se.

\section{Results}

\section{Selection of sources of evidence}

The selection of sources of evidence is shown in a PRISMA flow chart (Fig. 1) [8]. In total, 1646 records were identified by searching the databases MEDLINE, EMBASE and PsycINFO. One additional eligible record was identified through searching the references of a review. After screening titles, abstracts and full texts, 98 articles remained with 36 studies finally eligible. 


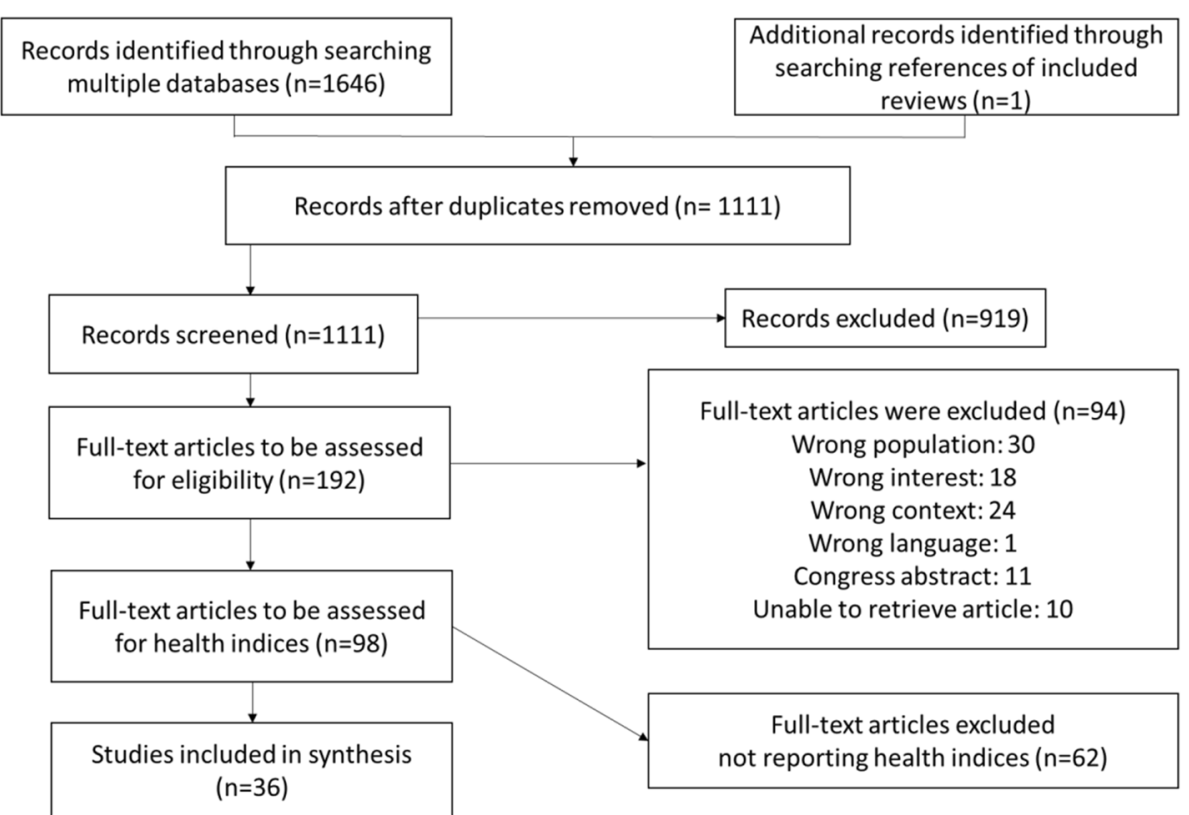

Fig. 1 PRISMA flow chart of studies identified, screened and included

\section{Characteristics of sources of evidence}

Table 1 shows the characteristics of studies with references and year of publication. The included studies were published from 1980 to 2019 and comprised study designs such as observational studies $(n=20)$, interventional studies $(n=8)$ and reviews $(n=8)$. Stratifying studies by WHO regions [12], most of the identified studies are from the Region of the Americas $(n=15$; $41.7 \%)$, followed by the European Region ( $n=11$; $30.6 \%)$, Eastern Mediterranean Region ( $n=4 ; 11.1 \%)$ and Western Pacific Region $(n=2 ; 5.6 \%)$. The most frequently reported context was school settings. The age of the populations in the studies ranged from 0 to 19 years. The number of persons per study ranges from 64 to 16,192 . In each study, between one to four indices were reported.

\section{Health indices with quality assessment}

Table 2 shows 18 identified indices with respective quality assessments in Table 3. Each index is assigned to a category that describes the overall theme. These thematic categories emerged from the data in a deductive process. In total, six different topic-specific categories for the 18 indices were chosen: namely Category 1: Anthropometrical Indices, Category 2: Special Indices for newborns, Category 3: Indices for oral health, Category 4: Indices on lifestyle, Category 5: Indices on functional ability and Category 6: Indices combining different aspects (such as prenatal, postnatal and behavioural aspects).

\section{Category 1: indices of anthropometrical variables}

We identified seven indices that we attributed as anthropometrical: body mass index (BMI) [13, 14, 16-20, 22, 24-26, 29, 30, 34-36, 38, 40, 44-46], BMI percentiles [13, $14,17,20,24,25,30,31,34,36,40,44-46]$, BMI z-scores [24, 35, 45], waist-to-height ratio [19], waist-to-hip ratio [20], mid-arm muscle circumference [13] and ponderal index [27].

The first three indices shown in Table 2 are the Body Mass Index (BMI), BMI percentiles for age and sex and BMI z-scores. The BMI is a measure for indicating nutritional status [48]. It is defined as weight in kilograms divided by the square of the height in metres [48]. BMI is also recommended for use in children and adolescents where the BMI is calculated and then compared with z-scores or percentiles [48]. Since the ratio between weight and height varies with sex and age during childhood and adolescence, the cut-off values that determine the nutritional status of those aged 0-19years are gender and age-specific [48]. In the definition of the WHO, "the cut-off points of the 2006 BMI-for-age reference for children aged 0-5 years for the diagnosis of overweight and obesity were set as the 97th and the 99th percentile, respectively. For those aged 5-19 years, overweight is defined as a BMI-for-age value over +1 SD and obesity as a BMI-for-age value over +2 SD." [48]. According to the identified studies and the WHO [48], the three indices provide face and construct validity, consistency and sensitivity. Regarding the consistency criteria, there are in fact standardized measuring procedures and this 
Table 1 Identified studies

\begin{tabular}{|c|c|c|c|c|c|c|}
\hline Authors & $\begin{array}{l}\text { Year of } \\
\text { publication }\end{array}$ & Study type & Country $^{\mathrm{a}}$ & Setting & $\begin{array}{l}\text { Population age } \\
\text { (years) }^{b}\end{array}$ & Indices in this paper \\
\hline $\begin{array}{l}\text { Abalkhail \& Shawky } \\
{[13]}\end{array}$ & 2002 & Observational & Saudi Arabia & Schools & $10-19$ & $\begin{array}{l}\text { BMI percentiles for age } \\
\text { and sex, } \\
\text { Mid-arm muscle cir- } \\
\text { cumference (MAMC) }\end{array}$ \\
\hline AlBuhairan et al. [14] & 2015 & Observational & Saudi Arabia & Schools & $10-19$ & $\begin{array}{l}\text { Body Mass Index (BMI), } \\
\text { BMI percentiles for age } \\
\text { and sex }\end{array}$ \\
\hline Antunes et al. [15] & 2004 & Observational & Brazil & n.a. ${ }^{c}$ & $11-12$ & $\begin{array}{l}\text { Decayed, missing and } \\
\text { filled teeth (DMFT), } \\
\text { Significant Caries Index } \\
\text { (SiC index) }\end{array}$ \\
\hline Ardic \& Erdogan [16] & 2017 & Interventional & Turkey & Schools & $12-15$ & Body Mass Index (BMI) \\
\hline Austin et al. [17] & 2007 & Interventional & USA & Schools & Grade 6-7 & $\begin{array}{l}\text { Body Mass Index (BMI), } \\
\text { BMI percentiles for age } \\
\text { and sex }\end{array}$ \\
\hline $\begin{array}{l}\text { Ayatollahi \& Bagheri } \\
\text { [18] }\end{array}$ & 2010 & Observational & Iran & School & $6.5-11.5$ & Body Mass Index (BMI) \\
\hline Bay et al. [19] & 2017 & Review & n.a. & Schools & n.a. & $\begin{array}{l}\text { Body Mass Index (BMI), } \\
\text { Waist-to-height ratio }\end{array}$ \\
\hline Beauchamp et al. [20] & 2011 & Interventional & Canada & Schools & Mean age 14.07 & $\begin{array}{l}\text { Body Mass Index (BMI), } \\
\text { BMI percentiles for age } \\
\text { and sex, } \\
\text { Waist-to-hip ratio }\end{array}$ \\
\hline Biscaglia et al. [21] & 2019 & Observational & $\begin{array}{l}\text { Jordan, Lebanon, } \\
\text { Syria, Gaza Strip and } \\
\text { West Bank }\end{array}$ & Schools & 12 & $\begin{array}{l}\text { Decayed, missing and } \\
\text { filled surfaces (DMFS), } \\
\text { Decayed, missing and } \\
\text { filled teeth (DMFT), } \\
\text { Significant Caries Index } \\
\text { (SiC index) }\end{array}$ \\
\hline Detty [22] & 2013 & Observational & USA & Schools & Grade 3 & Body Mass Index (BMI) \\
\hline Do \& Spencer [23] & 2007 & Observational & Australia & n.r. ${ }^{d}$ & $8-13$ & $\begin{array}{l}\text { Decayed, missing and } \\
\text { filled surfaces (DMFS) }\end{array}$ \\
\hline Elder et al. [24] & 2014 & Interventional & USA & Recreation centres & $5-8$ & $\begin{array}{l}\text { Body Mass Index (BMI), } \\
\text { BMI percentiles for age } \\
\text { and sex, BMI z-scores } \\
\text { for age and sex }\end{array}$ \\
\hline Flynn et al. [25] & 2006 & Review & n.a. & n.a. & n.a. & $\begin{array}{l}\text { Body Mass Index (BMI), } \\
\text { BMl percentiles for age } \\
\text { and sex }\end{array}$ \\
\hline Gardner et al. [26] & 2016 & Observational & Australia & n.a. & $0-16$ & Body Mass Index (BMI) \\
\hline Gissler et al. [27] & 1992 & Observational & Finland & n.a. & $0-7$ & $\begin{array}{l}\text { Ponderal index, 1-min } \\
\text { Apgar score, 5-min } \\
\text { Apgar score, perinatal } \\
\text { health index }\end{array}$ \\
\hline Greer et al. [28] & 2003 & Observational & USA & Schools & $5-9$ & $\begin{array}{l}\text { Decayed, missing and } \\
\text { filled teeth (DMFT) }\end{array}$ \\
\hline Hebestreit [29] & 2019 & Review & Europe & n.a. & n.a. & Body Mass Index (BMI) \\
\hline Kilanowski \& Lin [30] & 2014 & Interventional & USA & Schools & $11-17$ & $\begin{array}{l}\text { Body Mass Index (BMI), } \\
\text { BMl percentiles for age } \\
\text { and sex }\end{array}$ \\
\hline $\begin{array}{l}\text { Kilanowski \& Ryan- } \\
\text { Wenger [31] }\end{array}$ & 2007 & Observational & USA & n.a. & $0-12$ & $\begin{array}{l}\text { BMI percentiles for } \\
\text { age and sex, decayed, } \\
\text { missing and filled teeth } \\
\text { (DMFT) }\end{array}$ \\
\hline Kohen et al. [32] & 2007 & Observational & Canada & Schools & $4-11$ & $\begin{array}{l}\text { Health Utilities Index } \\
\text { (HUI) }\end{array}$ \\
\hline Köhler [33] & 2006 & Review & Sweden & n.a. & $0-19$ & $\begin{array}{l}\text { Health indicators for } \\
\text { Swedish children }\end{array}$ \\
\hline
\end{tabular}


Table 1 (continued)

\begin{tabular}{|c|c|c|c|c|c|c|}
\hline Authors & $\begin{array}{l}\text { Year of } \\
\text { publication }\end{array}$ & Study type & Country $^{a}$ & Setting & $\begin{array}{l}\text { Population age } \\
\text { (years) }^{\text {b }}\end{array}$ & Indices in this paper \\
\hline Köhler [1] & 2016 & Review & n.a. & n.a. & n.a. & $\begin{array}{l}\text { Health indicators for } \\
\text { Swedish children }\end{array}$ \\
\hline Koivusilta et al. [34] & 2006 & Observational & Finland & n.a. & $12-16$ & $\begin{array}{l}\text { Body Mass Index (BMI), } \\
\text { BMI percentiles for age } \\
\text { and sex }\end{array}$ \\
\hline Kulaga et al. [35] & 2010 & Observational & Poland & Schools & $6.5-18.5$ & $\begin{array}{l}\text { Body Mass Index (BMI), } \\
\text { BMI z-scores for age } \\
\text { and sex }\end{array}$ \\
\hline Kuntz \& Lampert [36] & 2013 & Observational & Germany & n.a. & $11-17$ & $\begin{array}{l}\text { Body Mass Index (BMI), } \\
\text { BMI percentiles for } \\
\text { age and sex, Healthy } \\
\text { Lifestyle Index (HLI) }\end{array}$ \\
\hline $\begin{array}{l}\text { Muratbegovic et al. } \\
\text { [37] }\end{array}$ & 2010 & Observational & $\begin{array}{l}\text { Bosnia and Herze- } \\
\text { govina }\end{array}$ & Communities & 6 & $\begin{array}{l}\text { Decayed, missing and } \\
\text { filled teeth (DMFT) }\end{array}$ \\
\hline Nyström et al. [38] & 2016 & Observational & Sweden & n.r. & $0-18$ & Body Mass Index (BMI) \\
\hline Ottolenghi et al. [39] & 2007 & Review & Europe & n.a. & n.a. & $\begin{array}{l}\text { Decayed, missing and } \\
\text { filled teeth (DMFT) }\end{array}$ \\
\hline $\begin{array}{l}\text { Peoples-Sheps et al. } \\
\text { [40] }\end{array}$ & 1998 & Review & USA & n.a. & $1-19$ & $\begin{array}{l}\text { Body Mass Index (BMI), } \\
\text { BMI percentiles for age } \\
\text { and sex }\end{array}$ \\
\hline Smadi [41] & 2017 & Observational & Jordan & Schools & $12-18$ & $\begin{array}{l}\text { Decayed, missing and } \\
\text { filled teeth (DMFT), } \\
\text { Significant Caries Index } \\
\text { (SiC index) }\end{array}$ \\
\hline Stamm [42] & 1980 & Review & Canada, USA & n.a. & n.a. & $\begin{array}{l}\text { Decayed, missing and } \\
\text { filled teeth (DMFT), deft } \\
\text { index (for primary/baby } \\
\text { teeth) }\end{array}$ \\
\hline Stamm et al. [43] & 1980 & Observational & Canada & n.a. & $13-14$ & $\begin{array}{l}\text { Decayed, missing and } \\
\text { filled teeth (DMFT), Oral } \\
\text { Hygiene Index (simpli- } \\
\text { fied) OHI(S) }\end{array}$ \\
\hline Tyler [44] & 2004 & Observational & USA & $\begin{array}{l}\text { School based health } \\
\text { centre }\end{array}$ & $7-12$ & $\begin{array}{l}\text { Body Mass Index (BMI), } \\
\text { BMI percentiles for age } \\
\text { and sex }\end{array}$ \\
\hline $\begin{array}{l}\text { Vogeltanz-Holm \& } \\
\text { Holm [45] }\end{array}$ & 2018 & Interventional & USA & Schools & Mean age 8.75 & $\begin{array}{l}\text { Body Mass Index (BMI), } \\
\text { BMI percentiles for age } \\
\text { and sex, BMI z-scores } \\
\text { for age and sex }\end{array}$ \\
\hline Whittemore et al. [46] & 2013 & Interventional & USA & Schools & $14-17$ & $\begin{array}{l}\text { Body Mass Index (BMI), } \\
\text { BMI percentiles for age } \\
\text { and sex }\end{array}$ \\
\hline $\begin{array}{l}\text { Wrobel \& Mielnik- } \\
\text { Blaszczak [47] }\end{array}$ & 2012 & Interventional & Poland & Schools & $12-13$ & $\begin{array}{l}\text { Decayed, missing and } \\
\text { filled surfaces (DMFS) }\end{array}$ \\
\hline
\end{tabular}

${ }^{\mathrm{a}}$ If there were no data on country but regions or continents, this information was noted in this column

${ }^{b}$ If there was no information on population age but on mean age or school grade, this information was noted in this column

c n.a. indicates that the information was not applicable

${ }^{d}$ n.r. indicates that the information was not reported

argument is used to justify consistency of the data [36], but this is not guaranteed if weight and height are selfreported by participants like in the study of Koivusilta et al. [34].

The waist-to-height ratio [19] is the waist circumference divided by the height in centimetres [50]. It is used for obesity assessment with the rationale that, for a given height, there is an acceptable degree of fat in the upper portion of the body [51]. It fulfils the quality criteria validity, consistency and sensitivity [49].

The waist-to-hip ratio is the waist circumference divided by the hip circumference [52]. It was suggested as an measure of body fat distribution and can be measured more precisely than skin folds [52]. After consulting 
Table 2 Identified Indices

\begin{tabular}{lll}
\hline Categories & Index & Variab \\
\hline Anthropometrical & Body Mass Index (BMI) & $\begin{array}{l}\text { Heigh } \\
\text { weight }\end{array}$
\end{tabular}

Height, weight

Anthropometrical BMl percentiles for age and sex

Anthropometrical BMI z-scores for age and sex

Anthropometrical Waist-to-height ratio

Anthropometrical Waist-to-hip ratio

Anthropometrical Mid-arm muscle circumference (MAMC)

Anthropometrical Ponderal index

Newborns 1-min Apgar score

Newborns $\quad$ 5-min Apgar score

Newborns $\quad$ Perinatal health index

Dental

Decayed, missing and filled surfaces (DMFS)

Dental

Decayed, missing and filled teeth (DMFT)

Dental

Significant Caries Index (SiC index)

Dental

Deft index (for primary/baby teeth)
Height,

weight

Height,

weight

Height,

waist circumference

Waist circumference,

hip circumference

Mid-arm circumference,

triceps skin fold thickness

Weight,

height

Appearance (skin colour), pulse (heart rate),

grimace response (reflexes), activity (muscle tone)

respiration (breathing rate and effort)

Appearance (skin colour),

pulse (heart rate),

grimace response (reflexes),

activity (muscle tone),

respiration (breathing rate and effort)

Birthweight, gestational age,

5-min Apgar score,

birthweight by gestational age,

perinatal diagnosis

Decayed surfaces (DS), missing surfaces (MS), filled surfaces (FS)

Decayed teeth (DT), missing teeth (MT), filled teeth (FT)

Decayed teeth/ surfaces (DT/S), missing teeth/surfaces (MT/S), filled teeth/surfaces (FT/S)

Decayed teeth, teeth extracted due to caries, filled teeth
References $^{a}$

Abalkhail \& Shawky, 2002 [13]; AlBuhairan et al. 2015 [14]; Ardic \& Erdogan, 2017 [16]; Austin et al., 2007 [17]; Ayatollahi \& Bagheri, 2010 [18]; Bay et al., 2017 [19]; Beauchamp et al., 2011 [20]; Detty, 2013 [22]; Elder et al, 2014 [24]; Flynn et al., 2006 [25]; Gardner et al., 2016 [26]; Hebestreit, 2019 [29]; Kilanowski \& Lin, 2014 [30]; Koivusilta et al., 2006 [34]; Kulaga et al., 2010 [35]; Kuntz \& Lampert, 2013 [36]; Nyström et al., 2016 [38]; Peoples-Sheps et al., 1998 [40]; Tyler, 2004 [44], Vogeltanz-Holm \& Holm, 2018 [45]; Whittemore et al.,2013 [46]

Abalkhail \& Shawky, 2002 [13]; AlBuhairan et al. 2015 [14]; Austin et al., 2007 [17]; Beauchamp et al., 2011 [20]; Elder et al., 2014 [24]; Flynn et al., 2006 [25]; Kilanowski \& Lin, 2014 [30]; Kilanowski \& Ryan-Wenger, 2007 [31]; Koivusilta et al., 2006 [34]; Kuntz \& Lampert, 2013 [36]; Peoples-Sheps et al., 1998 [40]; Tyler, 2004 [44]; Vogeltanz-Holm \& Holm, 2018 [45]; Whittemore et al.,2013 [46]

Elder et al., 2014 [24]; Kulaga et al., 2010 [35]; Vogeltanz-Holm \& Holm, 2018 [45]

Bay et al., 2017 [19]

Beauchamp et al., 2011 [20]

Abalkhail \& Shawky, 2002 [13]

Gissler et al., 1999 [27]

Gissler et al., 1999 [27]

Gissler et al., 1999 [27]

Gissler et al., 1999 [27]

Biscaglia et al., 2019 [21]; Do \& Spencer, 2007 [23]; Wrobel \& Mielnik-Blaszczak, 2012 [47]

Antunes et al., 2004 [15]; Biscaglia et al., 2019 [21]; Greer et al., 2003 [28]; Kilanowski \& Ryan-Wenger, 2007 [31]; Muratbegovic et al., 2010 [37]; Ottolenghi et al., 2007 [39]; Smadi, 2017 [41]; Stamm, 1980 [42]; Stamm et al., 1980 [43]

Antunes et al., 2004 [15]; Biscaglia et al., 2019 [21]; Smadi, 2017 [41];

Stamm, 1980 [42] 
Table 2 (continued)

\begin{tabular}{|c|c|c|c|}
\hline Categories & Index & Variables included in the index & References $^{a}$ \\
\hline Dental & Oral Hygiene Index (simplified) OHI(S) & $\begin{array}{l}\text { Debris score, } \\
\text { calculus score }\end{array}$ & Stamm et al., 1980 [43] \\
\hline Lifestyle & Healthy Lifestyle Index (HLI) & $\begin{array}{l}\text { Current tobacco consumption, } \\
\text { body mass index, } \\
\text { physical activity, } \\
\text { regular consumption of alcohol, } \\
\text { consumption of fresh fruit and vegeta- } \\
\text { bles, } \\
\text { daily use of electronic media: television/ } \\
\text { video, computer/internet and game } \\
\text { console }\end{array}$ & Kuntz \& Lampert, 2013 [36] \\
\hline Functional ability & Health Utilities Index (HUI) & $\begin{array}{l}\text { Vision, } \\
\text { hearing, } \\
\text { speech, } \\
\text { ambulation, } \\
\text { dexterity, } \\
\text { cognition, } \\
\text { emotion, } \\
\text { pain }\end{array}$ & Kohen et al., 2007 [32] \\
\hline $\begin{array}{l}\text { Combination of } \\
\text { different aspects }\end{array}$ & Health indicators for Swedish children & $\begin{array}{l}\text { Children injured by external causes, } \\
\text { children exposed to tobacco in the } \\
\text { womb, } \\
\text { children with low birthweight, } \\
\text { children that are breastfed, } \\
\text { teenage abortions, } \\
\text { children vaccinated against MPR (mea- } \\
\text { sles, parotitis and rubella) }\end{array}$ & Köhler, 2006 [1]; Köhler, 2016 [1] \\
\hline
\end{tabular}

${ }^{a}$ Reference of the studies identified in this scoping review reporting the index

further literature [52] on face validity, consistency and sensitivity, it can be stated that waist-to-hip ratio also meets most quality criteria.

The mid-arm muscle circumference (MAMC) is calculated using the mid-arm circumference and the triceps skin fold thickness and is used for the assessment of muscle content [13]. It is described as valid and consistent in the identified study [13], but lacks information on sensitivity.

The ponderal index is calculated as weight/lenght ${ }^{3}$ and is used to measure newborns' health [27]. It is a valid, consistent and sensitive measure [53].

\section{Category 2: special indices for newborns}

We identified three indices that we attributed as indices for newborns: The 1-min Apgar score [27], the 5-min Apgar score [27] and the perinatal health index [27].

The Apgar score is a rapid method for assessment immediately after birth and in response to resuscitation [54]. It includes information on skin colour, heart rate, reflexes, muscle tone and respiration [54]. Each category is scored 0,1 , or 2; the meaning of the scorings is defined for each category [54]. "The score is recorded at $1 \mathrm{~min}$ and $5 \mathrm{~min}$ in all infants with expanded recording at 5-min intervals for infants who score 7 or less at $5 \mathrm{~min}$, and in those requiring resuscitation as a method for monitoring response. Scores of 7 to 10 are considered reassuring. “ [54]. Referring to other literature [54], face validity is given, whereas consistency is not due to its high subjectivity and inter-rater variability [54].

The perinatal health index was developed by Gissler et al. [27] to investigate how well children's health can be predicted by perinatal outcomes. The index is calculated using information on birthweight, gestational age, 5-min Apgar score, birthweight by gestational age and perinatal diagnoses [27]. Each of the five categories is assessed and given a score [27]. The combined value of the five categories builds the final perinatal health index [27]. The index classifies the newborns studied into three categories: a healthy newborn; a newborn with some perinatal problem(s) which do not necessarily affect the subsequent health; a newborn with severe perinatal problems causing a major risk for subsequent health [27]. The perinatal health index is reported to not be a sensitive index [27]. It is stated to be a consistent index, however, with the limitation that the Apgar score is included in this index as discussed above [27].

\section{Category 3: indices for oral health}

We identified five indices that we attributed as dental: DMFS [21, 23, 47], DMFT [15, 21, 28, 31, 37, 39, 41-43], Significant Caries Index ( $\mathrm{SiC}$ index) [15, 21, 41], 


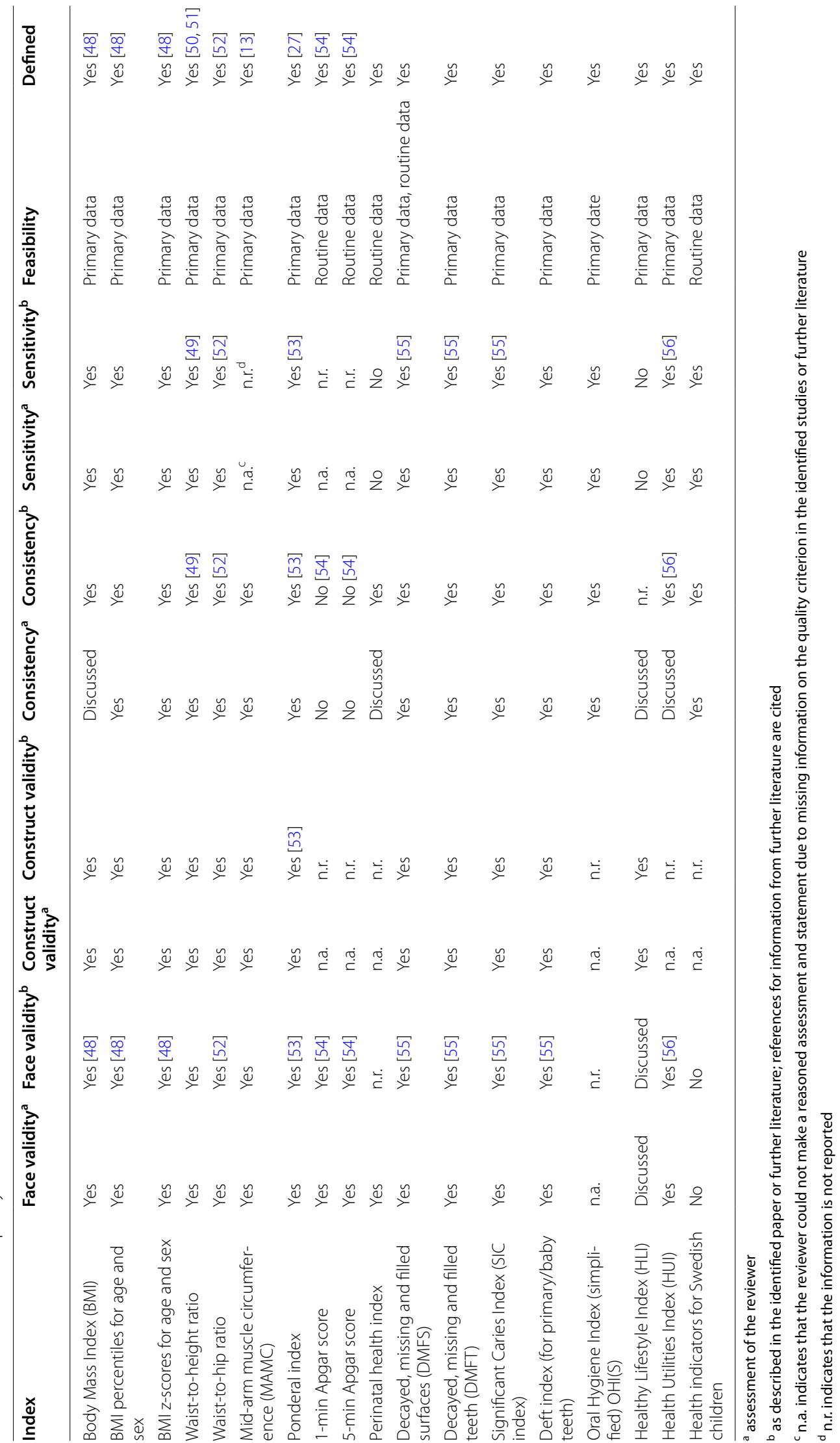


deft index [42] and the simplified Oral Hygiene Index $(\mathrm{OHI}(\mathrm{S}))$ [43].

The DMFS includes information on decayed, missing and filled surfaces [21, 23, 47] whereas the DMFT includes information on decayed, missing and filled teeth $[15,21,28,31,37,39,41-43]$. These indices indicate the number of teeth/surfaces that were affected by caries, filled or missing as a result of caries and are therefore used to assess dental caries [21]. The $\mathrm{SiC}$ index is defined as the mean of DMFT or DMFS for one-third of the study group with the highest caries scores $[15,21$, 41]. The deft index includes the variables decayed teeth, teeth extracted due to caries and filled teeth and is used for the caries assessment of primary/baby teeth [42]. The $\mathrm{OHI}(\mathrm{S})$ is used for oral hygiene assessment by examining the presence of plaque on the surface of the teeth witch is expressed in the two indicators debris and calculus score [43].

Of the five indices reporting on oral health, four met the quality criteria on validity, consistency and sensitivity. These are DMFT, DMFS, SiC index and deft index. Face validity and sensitivity were reported as good in published WHO literature on oral health surveys [55]. The $\mathrm{OHI}(\mathrm{S})$ is stated to be consistent and sensitive [43].

\section{Category 4: index on lifestyle}

We identified one index that focuses on lifestyle, the Healthy Lifestyle Index (HLI) [36]. The HLI is based on data regarding smoking behaviour, body mass index, physical activity, use of electronic media, alcohol intake and fruit and vegetable consumption [36]. The values of the six individual indicator constructs are assessed in a dichotomised way $(0=$ negative, $1=$ positive $)$ and then added into a composite score [36]. The index is described as being not sensitive, the construct validity is described as good whereas the face validity is under discussion [36]. As the HLI examines health-related behaviour, it is argued that at least some of the most important behaviour-based factors influencing health in adolescence are included [36]. Yet individual health behaviours, even when taken together, are not capable of fully reflecting a health-related lifestyle, since factors such as resources, orientations, attitudes, opinions and knowledge may also be important to be considered [36]. Regarding consistency, it should be noted that the index is based on selfreports of behaviour with the obvious limitations [36].

\section{Category 5: index on functional ability}

We identified one index that includes variables of functional ability, the Health Utilities Index (HUI) [32]. The HUI measures a child's ability to function within eight health domains and combines these into a single health utility dimension [32]. The assessed variables are vision, hearing, speech, ambulation, dexterity, cognition, emotion and pain [32]. Each attribute is scored from 1 (representing full ability) to a maximum of 5 or 6 (representing poor functional ability) [32]. Using an existing algorithm based on population norms, the scores for the eight health domains were combined to produce a composite score that assigned a numeric utility value to the individual's total health state, where 1.0 represented perfect health and 0.0 represented a health state equal to death [32]. Negative utility values are possible on the HUI, representing health states that are considered worse than death [32]. Face validity, consistency and sensitivity of the index are judged as good [56], however, consistency limited due to external evaluation by parents [32].

\section{Category 6: index combining prenatal, postnatal and behavioural aspects}

We identified one index attributed as a combination of different aspects, the Health Indicators for Swedish children $[1,33]$. A composite index is built by combining information on children injured by external causes, exposed to tobacco in the womb, with low birthweight, that are breastfed, vaccinated against MPR (measles, parotitis and rubella) as well as information on teenage abortions [33]. The results for each indicator are added and the sum is divided by six, which results in an index between 0 and 100 with 100 representing the best score [33]. The index is described as a consistent and sensitive index, but the face validity is not provided [33].

\section{Discussion}

With this scoping review, we provided an overview of the literature that report health indices on health outcomes and risk factors as well as health behaviour in children and adolescents. We identified and described these health indices and conducted quality appraisals of these indices.

In total, we identified 36 eligible studies and 18 health indices. The majority of the identified indices covered anthropometrical or dental variables. Furthermore, there were indices for newborns as well as indices assessing lifestyle and functional ability. One identified index combines different aspects out of all.

Interestingly, the number of indices identified was very limited.

Not all existing indicators for children and adolescents have been captured by our scoping review since these did not meet study's inclusion criteria of a composite index. However, none of the provided composite indices gives a complete picture of child and adolescent health. To function as effective tools for evaluating and monitoring health, this complex "state of complete physical, mental 
and social well-being" other essential indicators or subindices should be incorporated or added $[1,57]$.

Indeed, in our review, composite indices did not include many health determinants except in two indices (Healthy Lifestyle Index (HLI); Health Indicators for Swedish Children), despite of their importance for health monitoring $[4,26]$.

Also, the topic of injuries, a relevant area in child health [4] and leading cause of death, disability and burden in children, could only be found in one index parameter (children injured by external causes in the index Health Indicators for Swedish Children). However, several publications identified through our search reported on single indicators related to these topics (for examples cited in this review see the work by Peoples-Sheps et al. and Kohen et al. [32, 40]). However not covered by our search results, indices on child road safety have been published, such as the work by Gitelman et al. that describes the development of a composite index of child road safety in a municipality [58]. In addition, the European Child Safety Alliance developed child safety report cards as tools that were specifically designed to bring attention to child injury as a major public health issue [59]. They include single indicators and composite indices [59].

Although the scoping review focused on children and adolescents, some of the indices were not limited for use in this age group and might have therefore been excluded. It is noteworthy, that in most studies indices were calculated with primary data collection. This is an important aspect when evaluating their applicability in monitoring and evaluation of health prevention and promotion initiatives where routine data use would most desirable for feasibility reasons.

Most of the indices identified in this review consist of anthropometrical variables and were used to identify obesity in the studied population. Both generalized and abdominal obesity are associated with increased risk of morbidity and mortality [52]. The main cause of obesity-related deaths is cardiovascular disease, for which abdominal obesity is a predisposing factor [52]. BMI is the predominantly chosen indicator to measure body size and composition, and to diagnose underweight and overweight [52] as easy to measure and calculate tool [48]. However, alternative measures that reflect abdominal adiposity, such as waist circumference, waist-to-hip ratio and waist-to-height ratio, have been suggested as being superior to BMI in predicting cardiovascular disease risk [52]. This is based largely on the rationale that increased visceral adipose tissue is associated with a range of metabolic abnormalities that are risk factors for type 2 diabetes and cardiovascular diseases [52]. Since the waist circumference depends on the percentage of body fat in the abdomen and in children and adolescents growth influences this value, the waist-to-height ratio is often formed in this age group to increase the significance [52].

For assessing newborns' health, the Apgar score was reported. It remains a widely accepted method of assessment and is endorsed by both the American College of Obstetricians and Gynecologists and the American Academy of Pediatrics [54]. Apgar scores may vary with gestational age, birth weight, maternal medications, drug use or anaesthesia, and congenital anomalies [54]. Several components of the score are also subjective and prone to inter-rater variability [54]. Thus, the Apgar score is limited in that it provides somewhat subjective information about an infant's physiology at a point in time [54]. The perinatal health index predicted childhood health correctly for $79 \%$ [27] of the studied children. However the value of perinatal health data in predicting subsequent morbidity was questioned by Gissler et al. [27] and the index turned out to be more precise for predicting health [27].

We included indices with dental variables in this scoping review as an important aspect of health, since "oral health affects people physically and psychologically and influences how they grow, enjoy life, look, speak, chew, taste food and socialize, as well as their feelings of social well-being" [41].

There are difficulties and shortcomings in measuring children's and adolescents' health with indices when there are too few and too incomplete indicators [33]. In many cases, data are insufficient to describe the broad and complex area that children's and adolescents' health represents [33]. There is a lack in the availability of routine data [33] which can also be seen in this scoping review, since most of the studies identified reports on primary data collection. Besides, the list of composite indices that emerged from this review reflects the lack of availability of appropriate indicators and indices in some essential dimensions of child health and wellbeing in general. Even though we searched the database PsycINFO, we were unable to identify indices on mental health. In another study from Sweden as well as in other publications $[4,5,33,57,60]$, a lack of data on children's mental health is described as well. Furthermore, it is reported that information about children's physical environment and its impact on their health is stated and reliable data on cultural offerings and experiences are also very poor or lacking $[4,5,33,61]$. Other missing indicators and topics have been stressed in numerous indicators projects in the past, such as intentional injuries \& child abuse $[4,5,57,61]$, children's social development [5], social capital and its influence on child health and development [33,61], educational development \& school social environment $[4,5,62]$, biological determinants of child obesity [63] or the consideration of health 
promotion resources [64], amongst others. Thus, data availability is a central aspect to be considered when developing indicators and indices to monitor child's health $[33,61]$ and must be taken into account, as has been done in other indicators' selection processes [4, 29, 63]. Furthermore, the most valuable insights are provided by repeatedly measured indicators rather than single surveys $[1,61]$. Routinely conducted, continuous monitoring can inform about changes over time, allowing to identify some emerging issues or to monitor the effect of interventions $[5,61]$. Thus, the long-term availability of data remains an important prerequisite to the use of indicators and indices [65].

In some countries, health monitoring systems can rely on solid, widely available, and accessible health data [61]. In Germany, though, the problem of data availability in the field of health promotion monitoring and reporting still challenges researchers [66], especially on a local level, where more attention is needed $[67,68]$. Promising developments to address this issue are underway $[65,67]$.

\section{Strengths and limitations}

Limitations of our study were a) a broad study question with the potential to miss out certain papers because of the focus of the question on the presented PIC scheme with corresponding inclusion and exclusion criteria and key words in the search strategy, b) the selection and limitation to the reported databases with an emphasis on medical and/or health outputs and the potential to miss out certain reports or health reporting documents from other resources, i.e. grey literature or resources covering social sciences manuscripts, c) the acceptance of various formats of scientific literature with the limitation that the granularity of information differed according to the article format while d) some information such as quality appraisal information had to be retrieved through additional sources or were limited in scope and depth.

These limitations could have impacted our findings by various ways: we could have missed out certain indices and indicators that were not identified through the search strategy, included in papers that were not listed in the selected databases or excluded by us within the selection process. These could have mainly affected indices and indicators that cover adjacent areas such as social, environmental or educational topics that are undoubtedly very important for child health determination, but were not in the focus of this project. This might have led to an overemphasis of a "medical" or health view on our work.

In the future, this could be tackled by an even broader and deeper approach and scope of the work including additional key words and additional database searches such as like CINAHL and multidisciplinary databases like
Emerald. This would most likely lead to the identification of further categories in additional areas exceeding the six we named.

A rigorous expert consensus procedure such as a Delphi or focus group that goes beyond our literature quality appraisal would strengthen the impact and a priority setting of the mentioned indices and indicators. This would be helpful for the implementation in practice, i.e. in the surveillance and monitoring of child health projects.

\section{Conclusion}

In conclusion, this scoping review shows that indices may be pragmatic tools for monitoring and evaluating the health of children and adolescents, as well as to evaluate interventions in prevention and health promotion settings over time or between different groups [33]. Most indices identified were valid, consistent and sensitive. However, most indices would require primary data acquisition as prerequisite. Therefore, sets of single indicators of routine data will still have their role in monitoring children's and adolescents' health for the evaluation of preventive interventions. Easily available routine data of solid quality are necessary, both for single indicators and composite indices, to be able to provide relevant and effective tools to evaluate and monitor children's and adolescents' health in a society. A sensible selection of appropriate index and individual indicators adapted to given settings should be therefore made in any project through further reduction procedures (such as expert consensus).

\section{Abbreviations}

PRISMA-SCR: PRISMA Extension for Scoping Reviews; WHO: World Health Organization; SDGs: Sustainable Development Goals; OECD: Organisation for Economic Co-operation and Development; CHILD: Indicators of Life and Development; HPM: Community Health Monitoring Programme; BMI: Body mass index; HLI: Healthy Lifestyle Index; MAMC: Mid-arm muscle circumference; DMFS: Decayed, missing and filled surfaces; DMFT: Decayed, missing and filled teeth; SiC index: Significant Caries Index; $\mathrm{OHI}(\mathrm{S})$ : Oral Hygiene Index (simplified); HUI: Health Utilities Index.

\section{Supplementary Information}

The online version contains supplementary material available at https://doi. org/10.1186/s12889-021-12335-x.

Additional file 1: Supplementary file 1. Search strategy for MEDLINE, EMBASE and PsycINFO.

\section{Acknowledgements}

Not applicable.

\section{Authors' contributions}

CJS and MC supervised the project whereas all authors (AS, MC, SV, and CJS) were involved in the protocol development. AS, CJS and MC developed the search strategy. Database searches and citation searches were done by AS. All authors (AS, MC, SV and CJS) were involved in title and abstract screening as well as full-text screening and data extraction. AS did the narrative data 
synthesis which was checked by the coauthors (MC, SV, CJS). All authors (AS, $M C, S V$, and CJS) were involved in the manuscript preparation and read and approved the final manuscript.

\section{Funding}

Open Access funding enabled and organized by Projekt DEAL. Lehre@LMU has borne the costs of acquiring articles that are not freely accessible. They had no role in design of the study; collection, analysis, and interpretation of data; or in writing the manuscript.

\section{Availability of data and materials}

The publications assessed in the current study for eligibility (fulltext stage) are available in the OSF repository under the link (https://osf.io/nc5mt). Datasets used and/or analysed during the current study are available from the correspondingauthor on reasonable request.

\section{Declarations}

Ethics approval and consent to participate

Not applicable.

\section{Consent for publication}

Not applicable.

\section{Competing interests}

The authors declare that they have no competing interests.

\section{Author details}

${ }^{1}$ Institute for Medical Information Processing, Biometry and Epidemiology-IBE, Chair of Public Health and Health Services Research, LMU Munich, Munich, Germany. ${ }^{2}$ Pettenkofer School of Public Health, Munich, Germany.

\section{Received: 30 December 2020 Accepted: 28 November 2021}

\section{Published online: 20 December 2021}

\section{References}

1. Köhler L. Monitoring children's health and well-being by indicators and index: apples and oranges or fruit salad? Child Care Health Dev. 2016;42(6):798-808. https://doi.org/10.1111/cch.12373.

2. WHO. 2018 Global reference list of 100 core health indicators (plus health-related SDGs). Geneva: World Health Organization; 2018.

3. OECD. Health at a glance 2019. Paris: OECD Indicators; 2019.

4. Rigby M. Principles and challenges of child health and safety indicators. Int J Injury Control Safety Promot. 2005;12(2):71. https://doi.org/ 10.1080/15660970500073674.

5. Rigby MJ, Köhler LI, Blair ME, Metchler R. Child health indicators for Europe: a priority for a caring society. Eur J Pub Health. 2003;13(3 SUPPL):38-46. https://doi.org/10.1093/eurpub/13.suppl_1.38.

6. WHO: Constitution of the World Health Organization. 2006. https:// www.who.int/governance/eb/who_constitution_en.pdf. Accessed: 09 Aug 2021.

7. Hagerty MR, Land KC. The well-being of America's children: developing and improving the child and youth well-being index. Dordrecht Heidelberg New York London: Springer; 2012.

8. Tricco AC, Lillie E, Zarin W, O'Brien KK, Colquhoun H, Levac D, et al. PRISMA extension for scoping reviews (PRISMA-SCR): checklist and explanation. Ann Intern Med. 2018;169(7):467-73.

9. World Health Organization: Recognizing adolescence. 2014. https:// apps.who.int/adolescent/second-decade/section2/page1/recognizing-adolescence.html. Accessed: 20 Sept 2020.

10. Commission JRC-E. Handbook on constructing composite indicators: methodology and user guide. Paris: OECD publishing; 2008.

11. Ashraf K, Ng CJ, Teo CH, Goh KL. Population indices measuring health outcomes: a scoping review. J Glob Health. 2019;9(1):010405. https:// doi.org/10.7189/jogh.09.010405.

12. World Health Organization: Alphabetical List of WHO Member States. 2020. https://www.who.int/choice/demography/by_country/en/. Accessed: 25 Sept 2020.
13. Abalkhail B, Shawky S. Comparison between body mass index, triceps skin fold thickness and mid-arm muscle circumference in Saudi adolescents. Ann Saudi Med. 2002;22(5-6):324-8. https://doi.org/10.5144/ 0256-4947.2002.324.

14. AlBuhairan FS, Tamim H, Al Dubayee M, Aldhukair S, Al Shehri S, Tamimi W, et al. Time for an adolescent health surveillance system in Saudi Arabia: findings from "jeeluna". J Adolesc Health. 2015;57(3):263-9.

15. Antunes JL, Narvai PC, Nugent ZJ. Measuring inequalities in the distribution of dental caries. Community Dent Oral Epidemiol. 2004;32(1):41-8.

16. Ardic A, Erdogan S. The effectiveness of the COPE healthy lifestyles TEEN program: a school-based intervention in middle school adolescents with 12-month follow-up. J Adv Nurs. 2017;73(6):1377-89.

17. Austin SB, Kim J, Wiecha J, Troped PJ, Feldman HA, Peterson KE. School-based overweight preventive intervention lowers incidence of disordered weight-control behaviors in early adolescent girls. Arch Pediatr Adolesc Med. 2007;161(9):865-9.

18. Ayatollahi SMT, Bagheri Z. New trends in weight-for-height charts of shirazi school children in relation to the CDC reference data. Iran J Pediatr. 2010;20(4):407-12 PMID: 23056739; PMCID: PMC3446089.

19. Bay JL, Hipkins R, Siddiqi K, Huque R, Dixon R, Shirley D, et al. Schoolbased primary NCD risk reduction: education and public health perspectives. Health Promot Int. 2017;32(2):369-79. https://doi.org/10. 1093/heapro/daw096.

20. Beauchamp MR, Rhodes RE, Hua S, Morton KL, Kreutzer C, Liang JA, et al. Testing the effects of an expectancy-based intervention among adolescents: can placebos be used to enhance physical health? Psychol Health Med. 2011;16(4):405-17.

21. Biscaglia L, di Caccamo P, Terrenato I, Arrica MA, Seita A, Campus G. Oral health status and caries trend among 12-year old Palestine refugee students: results from the UNRWA's oral health surveys 2011 and 2016. BMC Oral Health. 2019;19(1):157.

22. Detty AM. School-based survey participation: oral health and BMI survey of Ohio third graders. Matern Child Health J. 2013;17(7):1208-14.

23. Do LG, Spencer A. Oral health-related quality of life of children by dental caries and fluorosis experience. J Public Health Dent. 2007;67(3):132-9.

24. Elder JP, Crespo NC, Corder K, Ayala GX, Slymen DJ, Lopez NV, et al. Childhood obesity prevention and control in city recreation centres and family homes: the MOVE/me M uevo P roject. Pediatr Obes. 2014;9(3):218-31.

25. Flynn M, McNeil D, Maloff B, Mutasingwa D, Wu M, Ford C, et al. Reducing obesity and related chronic disease risk in children and youth: a synthesis of evidence with 'best practice'recommendations. Obes Rev. 2006;7:7-66.

26. Gardner S, Woolfenden S, Callaghan L, Allende T, Winters J, Wong G, et al. Picture of the health status of Aboriginal children living in an urban setting of Sydney. Aust Health Rev. 2016;40(3):337-44.

27. Gissler $\mathrm{M}$, Järvelin $\mathrm{M}-\mathrm{R}$, Louhiala $\mathrm{P}$, Rahkonen $\mathrm{O}$, Hemminki E. Can children's health be predicted by perinatal health? Int J Epidemiol. 1999;28(2):276-80

28. Greer M, Tengan SL, Hu KI, Takata JT. Early childhood caries among Hawaii public school children, 1989 vs. 1999. Pacif Health Dialog. 2003;10(1):17 PMID: 16276937.

29. Hebestreit A, Thumann B, Wolters M, Bucksch J, Huybrechts I, Inchley J, et al. Road map towards a harmonized pan-European surveillance of obesity-related lifestyle behaviours and their determinants in children and adolescents. Int J Public Health. 2019;64(4):615-23.

30. Kilanowski JF, Lin L. Summer migrant students learn healthy choices through videography. J Sch Nurs. 2014;30(4):272-80.

31. Kilanowski JF, Ryan-Wenger NA. Health status in an invisible population: carnival and migrant worker children. West J Nurs Res. 2007;29(1):100-20.

32. Kohen DE, Brehaut JC, Garner RE, Miller AR, Lach LM, Klassen AF, et al. Conceptualizing childhood health problems using survey data: a comparison of key indicators. BMC Pediatr. 2007;7 (no pagination):40.

33. Köhler L. Health indicators for Swedish children. Save Child Sweden. 2006 https://resourcecentre.savethechildren.net/pdf/5263.pdf/.

34. Koivusilta LK, Rimpela AH, Kautiainen SM. Health inequality in adolescence. Does stratification occur by familial social background, family affluence, or personal social position? BMC Public Health. 2006;6 (no pagination): 110.

35. Kulaga Z, Litwin M, Tkaczyk M, Rozdzynska A, Barwicka K, Grajda A, et al. The height-, weight-, and BMI-for-age of polish school-aged children and 
adolescents relative to international and local growth references. BMC Public Health. 2010;10:109.

36. Kuntz B, Lampert T. How healthy is the lifestyle of adolescents in Germany? Gesundheitswesen (Bundesverband der Ärzte des Öffentlichen Gesundheitsdienstes (Germany)). 2013;75(2):67-76.

37. Muratbegovic AA, Markovic N, Zukanovic A, Kobaslija S, Dragas MS, Juric $\mathrm{H}$. Oral health related to demographic features in Bosnian children aged six. Coll Antropol. 2010;34(3):1027-33 PMID: 20977098.

38. Nyström CD, Larsson C, Ehrenblad B, Eneroth H, Eriksson U, Friberg M, et al. Results from Sweden's 2016 report card on physical activity for children and youth. J Phys Act Health. 2016;13(s2):S284-S90.

39. Ottolenghi L, Muller-Bolla M, Strohmenger L, Bourgeois D. Oral health indicators for children and adolescents: European perspectives. Eur J Paediatr Dent. 2007:8(4):205-10.

40. Peoples-Sheps MD, Guild PA, Farel AM, Cassady CE, Kennelly J, Potrzebowski PW, et al. Model indicators for maternal and child health: an overview of process, product, and applications. Matern Child Health J. 1998;2(4):241-56.

41. Smadi L. Oral health status and behaviour in Jordanian adolescents aged 12-18 years. Australas Med J. 2017:10(7):587-94.

42. Stamm J. Some indicators of oral health status of the north American child population. Can Dent Assoc J. 1980;46(1):21.

43. Stamm J, Dixter C, Langlais R. Principal dental health indices for 13-14 year old Quebec children. Can Dent Assoc J. 1980;46(2):125.

44. Tyler DO. Overweight and perceived health in Mexican American children: a pilot study in a Central Texas community. J Sch Nurs. 2004:20(5):285-92.

45. Vogeltanz-Holm N, Holm J. Changes in body mass index during a 3-year elementary school-based obesity prevention program for American Indian and white rural students. Health Educ Behav. 2018;45(2):277-85.

46. Whittemore R, Jeon S, Grey M. An internet obesity prevention program for adolescents. J Adolesc Health. 2013;52(4):439-47.

47. Wrobel R, Mielnik-Blaszczak M. Assessment of using additional means of oral hygiene on the state of the hard tissue of teeth in 12-13 year old children living in the Lublin province. Curr Issues Pharm Med Sci. 2012;25(1):49-51.

48. World Health Organization: Body mass index - BMI. 2020. https://www. euro.who.int/en/health-topics/disease-prevention/nutrition/a-healthylifestyle/body-mass-index-bmi. Accessed: 20 Sept 2020.

49. Taylor RW, Williams SM, Grant AM, Taylor BJ, Goulding A. Predictive ability of waist-to-height in relation to adiposity in children is not improved with age and sex-specific values. J Obes. 2011;19(5):1062-8.

50. Schneider HJ, Friedrich N, Klotsche J, Pieper L, Nauck M, John U, et al. The predictive value of different measures of obesity for incident cardiovascular events and mortality. J Clin Endocrinol Metab. 2010;95(4):1777-85.

51. da Silva Magalhães El, da Rocha Sant'Ana LF, Priore SE, Franceschini SCC. Waist circumference, waist/height ratio, and neck circumference as parameters of central obesity assessment in children. Rev Paul Pediatr. 2014;32(3):273-81. https://doi.org/10.1016/S2359-3482(15)30022-1.

52. WHO. Waist circumference and waist-hip ratio: report of a WHO expert consultation, Geneva, 8-11 December 2008. Geneva: World Health Organization; 2011. Report No.: 9241501499

53. Zaniqueli D, Oliosa PR, Neves FS, Pani VO, Martins CR, de Souza Pecanha $M A$, et al. Ponderal index classifies obesity in children and adolescents more accurately than body mass index z-scores. Pediatr Res. 2019;86(1):128-33.

54. Simon LV, Hashmi MF, Bragg BN. APGAR Score. StatPearls [Internet]: StatPearls Publishing; 2019. https://www.ncbi.nlm.nih.gov/books/NBK47 0569\%.

55. WHO. Oral health surveys: basic methods. Geneva: World Health Organization; 2013. Report No.: 9241548649

56. Horsman J, Furlong W, Feeny D, Torrance G. The health utilities index $\left(\mathrm{HU}{ }^{\circledR}\right)$ : concepts, measurement properties and applications. Health Qual Life Outcomes. 2003;1 (1):54.

57. Köhler L, Eriksson B. A child health index for Sweden's 290 municipalities. Child Indic Res. 2018;11(6):1889-906.

58. Gitelman V, Levi S, Doveh E, Endy-Findling L. Developing a composite index of child road safety in a municipality. Open I Saf Sci Technol. 2013;3(2):18-30.
59. MacKay M, Vincenten J. Child safety report card 2012: Europe summary for 31 countries; 2012. Birmingham: European Child Safety Alliance, Eurosafe; 2015

60. Goldfeld SR, Oberklaid F. Maintaining an agenda for children: the role of data in linking policy, politics and outcomes. Med J Aust. 2005;183(4):209-11.

61. Perou R, Bitsko RH, Blumberg SJ, Pastor P, Ghandour RM, Gfroerer JC, et al. Mental health surveillance among children - United States, 2005-2011. Centers Dis Control Prev Morb Mortal Wkly Rep. 2013;62(2):1-35 PMID: 23677130.

62. Leger LS. Developing indicators to enhance school health. Health Educ Res. 2000;15(6):719-28.

63. Varnaccia G, Zeiher J, Lange C, Jordan S. Adipositasrelevante Einflussfaktoren im Kindesalter-Aufbau eines bevölkerungsweiten Monitorings in Deutschland. J Health Monit. 2017;2(2):90-102 https://doi.org/10.17886/ RKI-GBE-2017-034.

64. Starker A, Perlitz H, Jordan S. Präventionsberichterstattung-Ihre Ziele, Akteure, Ansätze und Entwicklungen sowie Herausforderungen. Über Prävention berichten-aber wie? Methodenprobleme der Präventionsberichterstattung. Berlin: Robert Koch-Institut, Bayerisches Landesamt für Gesundheit und Lebensmittelsicherheit; 2020. p. 9-14.

65. Reisig V, Kuhn J. Präventionsindikatorensatz Bayern-Eckdaten zur Prävention für Bayern und seine Regionen. J Health Monit. 2018;2.

66. Kuhn J, Ziese T. Prävention, Präventionsberichterstattung, Methoden, Methodenprobleme. Über Prävention berichten-aber wie? Methodenprobleme der Präventionsberichterstattung. Berlin: Robert Koch-Institut, Bayerisches Landesamt für Gesundheit und Lebensmittelsicherheit; 2020. p. $5-8$.

67. Reisig V, Jordan S, Starker A, Brettner J, Kuhn J. Präventionsberichterstattung-neue Impulse für die Gesundheitsberichterstattung? Bundesgesundheitsblatt Gesundheitsforschung Gesundheitsschutz. 2020:1-8. https://doi.org/10.1007/s00103-020-03202-y.

68. Starke D, Arnold L, Szagun B. Kommunale Problemlagen im Spiegel der Zwischenbilanz des Präventionsgesetzes. Über Prävention berichtenaber wie? Methodenprobleme der Präventionsberichterstattung. Berlin: Robert Koch-Institut, Bayerisches Landesamt für Gesundheit und Lebensmittelsicherheit; 2020. p. 23-30.

\section{Publisher's Note}

Springer Nature remains neutral with regard to jurisdictional claims in published maps and institutional affiliations.

Ready to submit your research? Choose BMC and benefit from

- fast, convenient online submission

- thorough peer review by experienced researchers in your field

- rapid publication on acceptance

- support for research data, including large and complex data types

- gold Open Access which fosters wider collaboration and increased citations

- maximum visibility for your research: over $100 \mathrm{M}$ website views per year

At BMC, research is always in progress.

Learn more biomedcentral.com/submissions 